\title{
Physiological and biochemical responses of photomorphogenic tomato mutants (cv. Micro-Tom) under water withholding
}

\author{
Frederico Rocha Rodrigues Alves ${ }^{1} \cdot$ Hyrandir Cabral de Melo ${ }^{1} \cdot$ Ailton José Crispim-Filho $^{2} \cdot$ \\ Alan Carlos Costa $^{2} \cdot$ Kelly Juliane Telles Nascimento ${ }^{2} \cdot$ Rogério Falleiros Carvalho $^{3}$
}

Received: 26 November 2015/Revised: 10 March 2016/Accepted: 12 May 2016/Published online: 27 May 2016

(C) Franciszek Górski Institute of Plant Physiology, Polish Academy of Sciences, Kraków 2016

\begin{abstract}
In addition to mediating photomorphogenesis, phytochromes are responsible for many abiotic stress responses, acting upon biochemical and molecular mechanisms of cell signaling. In this work, we measured the physiological and biochemical responses of phytochromemutant plants under water stress. In tomato (Solanum lycopersicum L.), the aurea mutant (au) is phytochromedeficient and the high-pigment-1 mutant (hpl) has exaggerated light responses. We examined the effects of water withholding on water potential, leaf gas exchange, chlorophyll fluorescence, chloroplast pigment content and antioxidant enzyme activity in $a u$ and $h p l$ and their wildtype cultivar Micro-Tom (MT). Initial fluorescence and potential quantum efficiency of photosystem II (PSII) photochemistry were not affected by the treatment, but effective quantum yield of PSII, electron transport rate decreased and non-photochemical quenching increased significantly in MT. Under water withholding conditions, MT had higher malondialdehyde concentration than the
\end{abstract}

Communicated by LA Kleczkowski.

Frederico Rocha Rodrigues Alves

fred.rra7@gmail.com

1 Laboratório de Fisiologia Vegetal, Instituto de Ciências Biológicas, Universidade Federal de Goiás, Avenida Esperança, s/n, Setor Itatiaia, Goiânia, Goiás 74690-900, Brazil

2 Laboratório de Ecofisiologia e Produtividade Vegetal, Instituto Federal Goiano, Rod. Sul Goiana Km 01, Zona Rural, Rio Verde 75.901-970, Goiás, Brazil

3 Departamento de Biologia Aplicada à Agropecuária, Faculdade de Ciências Agrárias e Veterinárias, Universidade Estadual Paulista "Júlio de Mesquita Filho", Via de Acesso Prof.Paulo Donato Castellane, s/n, Jaboticabal, São Paulo 14884-900, Brazil mutants, but $a u$ had higher activities of catalase and ascorbate peroxidase compared to the other genotypes. The tolerance of mutants to the effects of water withholding may be explained by the higher activity of antioxidant enzymes in $a u$ and by a higher concentration of antioxidant compounds, such as carotenoids, in $h p l$.

Keywords Aurea $\cdot$ High-pigment-1 $\cdot$ Chlorophyll fluorescence $\cdot$ Antioxidant enzymes

\section{Introduction}

Phytochromes are plant pigments capable of absorbing light in the red and far-red region, between 660 and $730 \mathrm{~nm}$ (Hughes 2010). These pigments play important roles as biochemical intermediates between light perception and plant development (Castillon et al. 2007). The role of phytochromes can be studied in plants that exhibit specific mutations related to the biosynthesis or the signal transduction of this photoreceptor. These mutants, which are referred to as photomorphogenic, can help determine if a given response or physiological process under study is influenced by phytochrome activity. In tomato (Solanum lycopersicum L.), the aurea (au) mutant is phytochrome deficient (Terry and Kendrick 1996; Muramoto et al. 2005), while the highpigment-l ( $h \mathrm{pl}$ ) mutant is highly sensitive to light-dependent responses (Kendrick et al. 1997; Liu et al. 2004).

In addition to their importance for photomorphogenesis, recent discoveries have also linked phytochromes to responses triggered by abiotic stresses, such as drought, due to their role in regulating the activity of enzymes and the transcription of specific genes, altering molecular and biochemical mechanisms of cell signaling (Schopfer 1977; Carvalho et al. 2011b). 
Drought is an important environmental constraint for plant growth and development. Decreased water availability impacts plant metabolism by disrupting water absorption and photosynthesis (Murshed et al. 2013). Phytochromes are associated with a number of morphological and physiological responses that mediate the absorption, transport and loss of water, in addition to carbon gain. In potato plants under field conditions, overexpression of phytochrome $\mathrm{B}$ increased stomatal conductance, photosynthesis and transpiration rates (Boccalandro et al. 2003), and was related to positive regulation of stomatal developmental genes, which affect the opening (Wang et al. 2010) and density (Boccalandro et al. 2009) of stomata in Arabidopsis. Phytochrome A is a key factor promoting xylem vessel diameter in tomato, which increases water conductance to the leaves of plants under high transpiration conditions (Auge et al. 2012), a function also carried out by phytochrome B in adult cucumber plants (Casal et al. 1994).

Carbon dioxide limitation in water-stressed plants, which results from a decrease in stomatal conductance (Smirnoff 1993), causes over-reduction of the photosynthetic electron transport chain, redirecting excess energy towards the production of reactive oxygen species (ROS). ROS can directly attack membrane lipids, damage nucleic acids and inactivate metabolic enzymes, ultimately leading to cell death (Gill and Tuteja 2010). The defense system of plants against ROS includes both enzymatic and non-enzymatic components, but when the production of ROS exceeds the capacity of the cells to remove them they cause oxidative stress (Noctor and Foyer 1998; Ahmad et al. 2010).

The regulation of ROS defenses is also associated with phytochromes, because they influence the activity of antioxidant enzymes (Schopfer 1977), such as ascorbate peroxidase (Thomsen et al. 1992; Mullineaux et al. 2000), catalase (Drumm and Schopfer 1974; Zhong et al. 1994), phenylalanine ammonia lyase (Wellmann and Schopfer 1975; Mohr et al. 1979; Jones 1984), and peroxidase (Sharma et al. 1976), in addition to regulating important non-enzymatic defenses such as carotenoids (Toledo-Ortiz et al. 2010).

Which phytochromes are involved in drought stress signaling and how this process works are trending research topics (D'Amico-Damião et al. 2015). A detailed knowledge of the physiological and biochemical processes that regulate the metabolic machinery of photomorphogenic mutants under different water regimes may provide insights into how phytochromes and related light-dependent signaling are related to drought tolerance responses. Given that phytochromes are associated with a number of morpho-physiological features that influence water relations and stress defenses, we expect a phytochrome- deficient mutant, such as $a u$, to have different strategies to cope with stress from water withholding than a mutant with increased photomorphogenic responses, such as $h p l$. How does water withholding stress affect each tomato genotype? Do responses differ among genotypes within the same treatments (control or stress)?

The objective of the present work is to determine and explain the effects of water withholding on physiological (gas exchange and chlorophyll fluorescence parameters) and biochemical (antioxidant enzyme activity) responses of two photomorphogenic mutants of tomato cv. Micro-Tom, aurea and high-pigment-1, and its wild-type cultivar.

\section{Materials and methods}

\section{Plant material and treatments}

Seeds of the wild-type tomato (Solanum lycopersicum L.) cultivar Micro-Tom (MT) and its photomorphogenic mutants $a u$ and $h p l$ were sown in trays containing a 2:1 dystroferric redmixture $(\mathrm{v}: \mathrm{v})$ of commercial potting mix (Bioplant ${ }^{\circledR}$, Nova Ponte, MG, Brazil) and expanded vermiculite supplemented with $1 \mathrm{~g} \mathrm{~L}^{-1}$ of NPK fertilizer 10-10-10 (the numbers separated by dashes describe the percentage of nitrogen, phosphorus and potassium in the product). Throughout the experiment period, plants were grown and maintained in a greenhouse under controlled conditions of temperature $\left(24-27^{\circ} \mathrm{C}\right)$, humidity $(60-80 \%)$ and photoperiod $(13 \mathrm{~h}$ day/11 $\mathrm{h}$ night). Two weeks after germination, the seedlings were transferred to $1 \mathrm{~L}$ pots containing a 2:1 mixture (v:v) of latosol and sand. The $\mathrm{pH}$ level and nutrient content were chemically adjusted to obtain the ideal conditions for tomato culture. The pots were arranged $20 \mathrm{~cm}$ apart to avoid shading.

In order to establish the stress treatment, regular irrigation was suspended for one group of 35-day-old plants comprising five plants per genotype (MT, $a u$ and $h p l$ ). As a control, another group of the same size was kept under normal water availability (close to the field capacity of the potting mix). The water withholding treatment lasted 5 days and the analysis were carried out on specific days during the treatment (described below).

\section{Leaf water status, gas exchange and fluorescence measurements}

Leaf water potential was measured from 4:00 a.m. to 6:00 a.m. with a Scholander pressure chamber. Measurements were taken on the fourth leaf from the shoot apex of four plants of each combination of genotype and treatment. Water potential analyses were carried out only once, on the fifth day of the water withholding experiment. 
Photosynthetic rate $\left(A, \mu \mathrm{mol} \mathrm{m} \mathrm{m}^{-2} \mathrm{~s}^{-1}\right)$, stomatal conductance $\left(\mathrm{gs}, \mathrm{mol} \mathrm{H}_{2} \mathrm{O} \mathrm{m} \mathrm{m}^{-2} \mathrm{~s}^{-1}\right)$ and transpiration rate $(E$, mmol m$\left.~^{-2} \mathrm{~s}^{-1}\right)$ were always measured between 8:00 a.m. and 10:30 a.m. on the second fully expanded leaf from the shoot apex of five individuals of each combination of genotype and treatment. Measurements were taken daily for the 5 days of the water withholding experiment, except for the second day, due to inappropriate weather conditions. We used a portable LI-6400XTR infrared gas analyzer (LI-COR Biosciences, Lincoln, NE, USA) adjusted to a constant chamber temperature of $24{ }^{\circ} \mathrm{C}$ and an attached LED light source to provide $1000 \mu \mathrm{mol}$ photons $\mathrm{m}^{-2} \mathrm{~s}^{-1}$. The leaves were placed in a $6 \mathrm{~cm}^{2}$ chamber and data were recorded every $10 \mathrm{~s}$ for $1 \mathrm{~min}$. The five measurements for each individual were averaged before recording the gas exchange parameters.

Chlorophyll fluorescence parameters were measured on the third fully expanded leaf from the shoot apex of the same individuals chosen for the gas exchange analysis. Data were collected daily for the duration of the experiment using a portable fluorometer MINI-PAM (Walz, Effeltrich, Germany). Analyses followed the methods proposed by Bilger et al. (1995) and Rascher et al. (2000) and the fluorescence terminology was updated according to the review by Baker (2008). First, leaves were acclimated to the dark for $30 \mathrm{~min}$. Next, they were exposed to a weak pulse of red light $\left(0.03 \mu \mathrm{mol} \mathrm{m} \mathrm{m}^{-2} \mathrm{~s}^{-1}\right)$ and the initial fluorescence (Fo) was measured. Finally, the leaves were exposed to $0.8 \mathrm{~s}$ of saturating actinic light ( $>6000 \mu \mathrm{mol} \mathrm{m} \mathrm{m}^{-2} \mathrm{~s}^{-1}$ ) and the maximum fluorescence was measured $\left(F_{\mathrm{m}}\right)$. Using these data, the effective quantum yield of PSII (Genty et al. 1989) was determined by superimposing a saturating pulse on leaves previously acclimated to ambient light and calculating $F_{\mathrm{q}}{ }^{\prime} / F_{\mathrm{m}-}$ $=\left(F_{\mathrm{m}}{ }^{\prime}-F\right) / F_{\mathrm{m}}{ }^{\prime}$, where $F_{\mathrm{m}}{ }^{\prime}$ is the maximum fluorescence during the saturating pulse and $\mathrm{F}$, the steady state fluorescence value before the saturation pulse. The $F_{\mathrm{q}}{ }^{\prime} / F_{\mathrm{m}}{ }^{\prime}$ parameter was then used to estimate the apparent electron transport rate (ETR) following Bilger et al. (1995), using the equation $\mathrm{ETR}=F_{\mathrm{q}}{ }^{\prime} / F_{\mathrm{m}}{ }^{\prime} \times \mathrm{PFD} \times 0.5 \times 0.84$, where PFD is the photon flux density incident on the leaf, 0.5 is the fraction of excitation energy distributed to PSII (Laisk and Loreto 1996) and 0.84 is the fraction of incident light absorbed by the leaves (Ehleringer 1981). The Non-Photochemical Quenching coefficient (NPQ) was calculated as $\mathrm{NPQ}=\left(F_{\mathrm{m}}-F_{\mathrm{m}}{ }^{\prime}\right) / F_{\mathrm{m}}{ }^{\prime}$ (Bilger and Björkman 1990).

\section{Photosynthetic pigment determination and malondialdehyde content}

The photosynthetic pigment content was determined through the extraction by dimethyl sulfoxide (DMSO), following Silva et al. (2014). Absorbance readings were taken in a UV-VIS Evolution $60 \mathrm{~S}$ spectrophotometer (Thermo Fisher Scientific, Madison, WI, USA). The calculations used to determine the content of chlorophyll $a$, chlorophyll $b$ and carotenoids are described in Wellburn (1994).

Lipid peroxidation was measured through the content of malondialdehyde (MDA), using the method of Heath and Packer (1968). For this procedure, $200 \mathrm{mg}$ of leaves were collected on the fifth day of the water withholding experiment from four plants of each combination of genotype and treatment. Absorbance was measured at 535 and $600 \mathrm{~nm}$, and MDA content was calculated using an extinction coefficient of $155 \mathrm{mM}^{-1} \mathrm{~cm}^{-1}$. Content was expressed as $\mathrm{nmol} \mathrm{g}^{-1} \mathrm{FW}$.

\section{Enzyme activity}

The following steps were carried out at $4{ }^{\circ} \mathrm{C}$ unless stated otherwise. For the enzyme extraction, $300 \mathrm{mg}$ of leaves were collected on the fifth day of the water withholding experiment from four different plants of each combination of genotype and treatment. Leaves were ground in liquid nitrogen with a mortar and pestle and homogenized in $2 \mathrm{~mL}$ of extraction mixture containing $100 \mathrm{mM}$ potassium phosphate buffer (pH 6.8), $0.1 \mathrm{mM}$ EDTA, $100 \mathrm{mM}$ phenylmethylsulfonyl fluoride and $2 \%$ (w/v) polyvinylpyrrolidone. The homogenate was filtered and centrifuged at $15,000 \mathrm{~g}$ for $15 \mathrm{~min}$. The supernatant was stored in separated aliquots at $-80{ }^{\circ} \mathrm{C}$ prior to enzymatic analyses. The protein concentration in each sample was determined by the Bradford method (Bradford 1976), using bovine serum albumin as a standard. Absorbance readings were taken with an Evolution 60 spectrophotometer (Thermo Scientific, Waltham, MA, USA).

Catalase (CAT) activity was assayed following the methods described by Havir and McHale (1987) and Azevedo et al. (1998), with a few modifications. The $1 \mathrm{~mL}$ reaction mixture contained $25 \mu \mathrm{L}$ of enzyme extract, $50 \mathrm{mM}$ potassium phosphate buffer $(\mathrm{pH} \mathrm{7}), 350 \mu \mathrm{L}$ of deionized water and $15.625 \mathrm{mM}$ hydrogen peroxide $(30 \%$ solution).

Ascorbate peroxidase (APX) activity was determined as described by Nakano and Asada (1981), with a few modifications. The $1 \mathrm{~mL}$ reaction mixture was composed of 50 $\mu \mathrm{L}$ of enzyme extract, $50 \mathrm{mM}$ potassium phosphate buffer (pH 6), $280 \mu \mathrm{L}$ of deionized water, $0.8 \mathrm{mM}$ ascorbate and $1.25 \mathrm{mM}$ hydrogen peroxide (30\% solution).

Superoxide dismutase (SOD) activity was assayed following the method of Giannopolitis and Ries (1977), based on the ability of the enzyme to inhibit the photochemical reduction of nitroblue tetrazolium (NBT). The $2 \mathrm{~mL}$ reaction solution contained $50 \mu \mathrm{L}$ of enzyme extract, $50 \mathrm{mM}$ potassium phosphate buffer ( $\mathrm{pH} 7.8$ ), $13 \mathrm{mM}$ 
methionine, $0.075 \mathrm{mM}$ NBT, $0.1 \mathrm{mM}$ EDTA, $150 \mu \mathrm{L}$ of deionized water and $0.002 \mathrm{mM}$ riboflavin. The tubes were irradiated for $10 \mathrm{~min}$.

Phenylalanine ammonia lyase (PAL) activity was determined by modifying the protocol established by Zucker (1965). The reaction mixture contained $100 \mu \mathrm{L}$ of enzyme extract and $900 \mu \mathrm{L}$ of $40 \mathrm{mM}$ borate buffer $(\mathrm{pH}$ 8.8 ) and $20 \mathrm{mM}$ phenylalanine. The mixture was incubated for $1 \mathrm{~h}$ at $30{ }^{\circ} \mathrm{C}$ and the reaction was stopped by adding 50 $\mu \mathrm{L}$ of $6 \mathrm{~N} \mathrm{HCl}$.

Peroxidase (POX) activity was assayed as described by Chance and Maehly (1955) and Kar and Mishra (1976). The $2 \mathrm{~mL}$ reaction mixture contained $15 \mu \mathrm{L}$ of enzyme extract, $885 \mu \mathrm{L}$ of deionized water, $26 \mathrm{mM}$ potassium phosphate buffer $(\mathrm{pH} 6.8), 21 \mathrm{mM}$ hydrogen peroxide (30\% solution) and $12.5 \mathrm{mM}$ pyrogallol.

\section{Statistical analysis}

The design of the experiment was completely randomized. Data were analyzed using two-way repeated measures ANOVAs, and the statistical significance of the differences between means within the same group (treatment or genotype) for each day was tested using Tukey's HSD test $(P<0.05)$. Three replicates of each reaction were used for photosynthetic pigment determination, MDA content and enzyme activity analyses. Statistical analyses were performed using SPSS version 20 (SPSS Inc., USA).

\section{Results}

\section{Water potential}

The water withholding treatment decreased leaf water potential of all tomato genotypes compared to the control (Fig. 1). Therefore, the comparisons between control and stress treatments presented below reflect a real effect of water limitation on plants.

No differences in water potential among genotypes within either the control or the stress treatments were observed, demonstrating that the mutations did not influence this parameter.

\section{Gas exchange}

Water withholding decreased photosynthetic rate (Fig. 2a) and stomatal conductance (Fig. 2b) in all genotypes from the fourth day of the experiment on, except for the $a u$ mutant, where significant differences only appeared on the fifth day. The same patterns were observed for transpiration

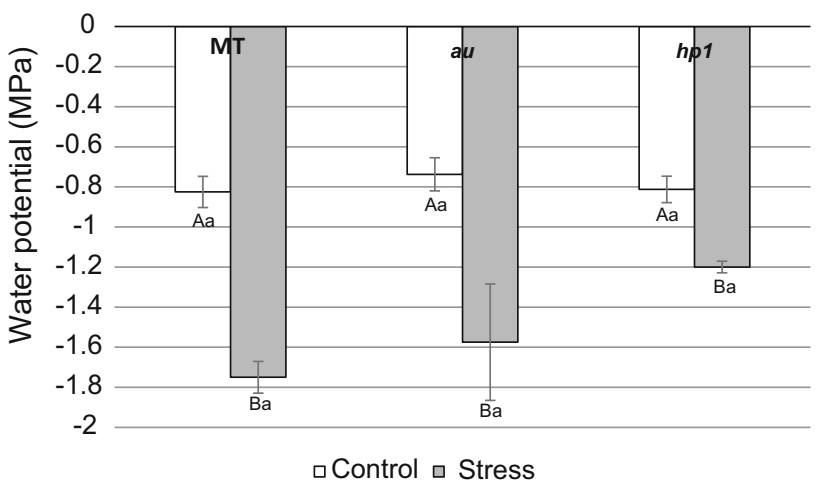

Fig. 1 Leaf water potential (in MPa) of the wild-type genotype (MT) and the aurea (au) and high-pigment-1 (hpl) mutants of tomato cv. Micro-Tom under normal water availability (control) and under water withholding for 5 days (stress). Bars indicate standard error, $n=4$. Significant differences are indicated by different letters (Tukey's test, $P<0.05)$. Upper case letters indicate comparisons between the control and stress treatments within the same genotype. Lower case letters indicate comparisons among genotypes under the same treatment (control or stress)

rates (Fig. 2c), which were significantly lower in plants under water withholding of all genotypes from the fourth day on.

Gas exchange parameters were not significantly different among genotypes under the same treatment (control or stress) (Fig. 2). The only exception was observed in the hpl mutant, where plants under the water withholding treatment had higher transpiration rates than MT on the fourth day (Fig. 2c), coinciding with higher values of stomatal conductance.

\section{Chlorophyll fluorescence}

During the whole experiment, the $a u$ mutant had lower initial fluorescence (Fo) than the other genotypes under normal water availability (Fig. 3a). The effects of water withholding were different for each genotype. Initial fluorescence (Fo) (Fig. 3a) and potential quantum efficiency of PSII (given by the $F_{\mathrm{v}} / F_{\mathrm{m}}$ ratio) (Fig. 3b) were not affected by the stress treatment in any of the genotypes, but PSII operating efficiency $\left(F_{\mathrm{q}}{ }^{\prime} / F_{\mathrm{m}}{ }^{\prime}\right.$, Fig. $\left.3 \mathrm{c}\right)$ and electron transport rate (ETR, Fig. 4a) decreased significantly in MT. In addition, the MT genotype was the first to increase its nonphotochemical quenching (NPQ) levels, diverging from the other genotypes from the third day of the experiment on (Fig. 4b). The tomato mutants kept the electron transport chain (ETC) running normally throughout the water withholding period (Fig. 4a), and their PSII operating efficiency was comparable to that of individuals in the control treatment (Fig. 3c). 
A 30
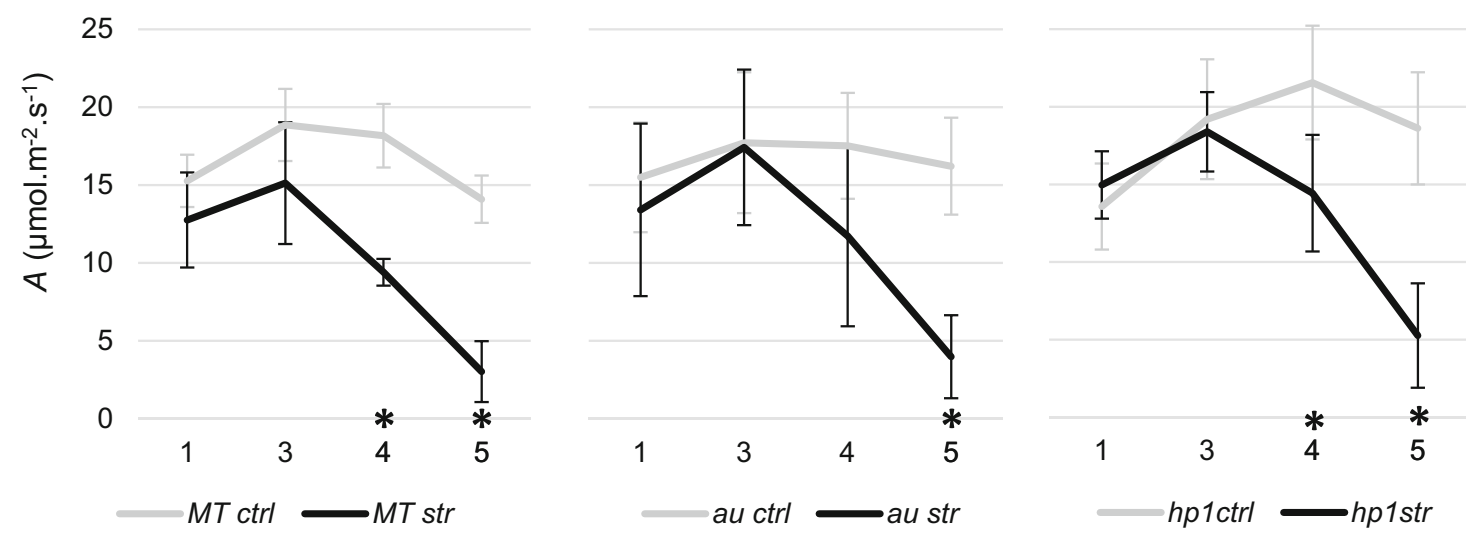

B
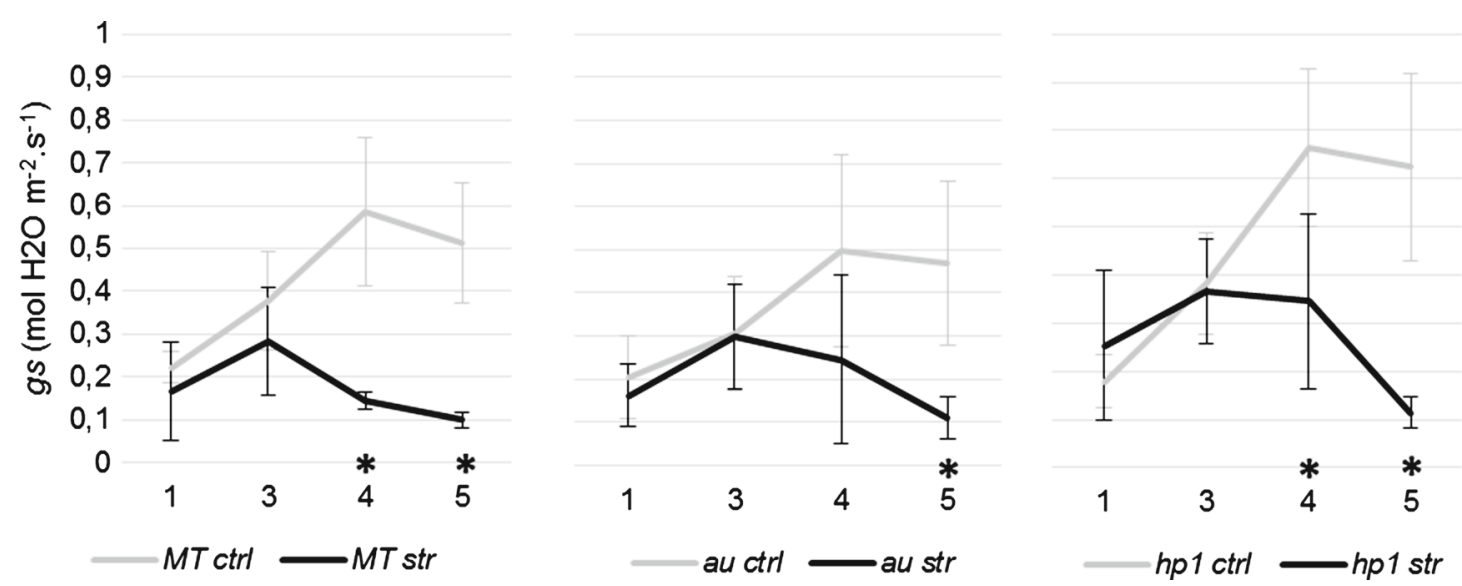

C

12

10

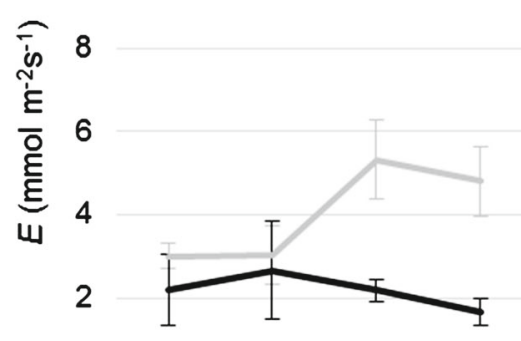

0

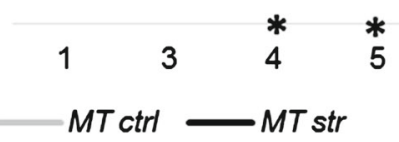

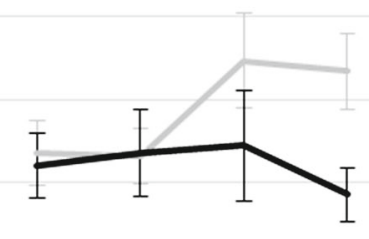

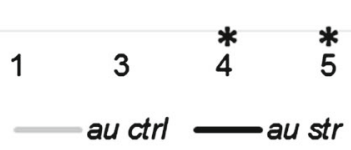

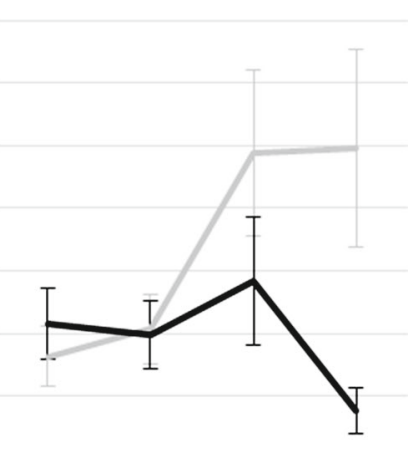

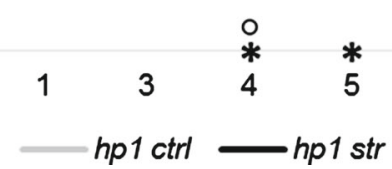

Fig. 2 Photosynthetic rate $\left(A\right.$, in $\left.\mu \mathrm{mol} \mathrm{m}^{-2} \mathrm{~s}^{-1}\right)$ (a), stomatal conductance (gs, in $\left.\mathrm{mol} \mathrm{H}_{2} \mathrm{O} \mathrm{m}^{-2} \mathrm{~s}^{-1}\right)(\mathbf{b})$, and transpiration rate $(E$, in $\mathrm{mmol} \mathrm{m} \mathrm{m}^{-1} \mathrm{~s}^{-1}$ ) (c) of the leaves of the wild-type genotype (MT) and aurea (au) and high-pigment-1 ( $h p l)$ mutants of tomato cv. Micro-Tom under normal water availability (ctrl gray line) or water withholding for 5 days (str black line). Bars indicate standard error, $n=5$. Each day of the experiment (on the horizontal axis) was compared separately. Different symbols indicate significant differences (ANOVA followed by Tukey's test, $P<0.05$ ). Asterisks were used for comparisons between the control and stress treatments within the same genotype, and circles for comparisons among genotypes under the stress treatment. The absence of symbols indicates that no significant differences were found 


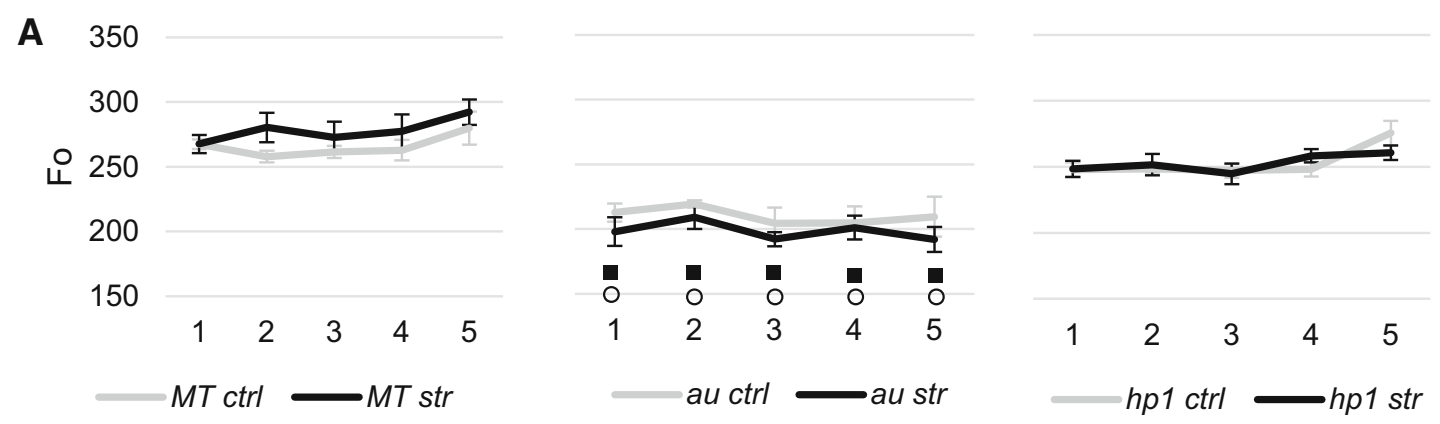

B
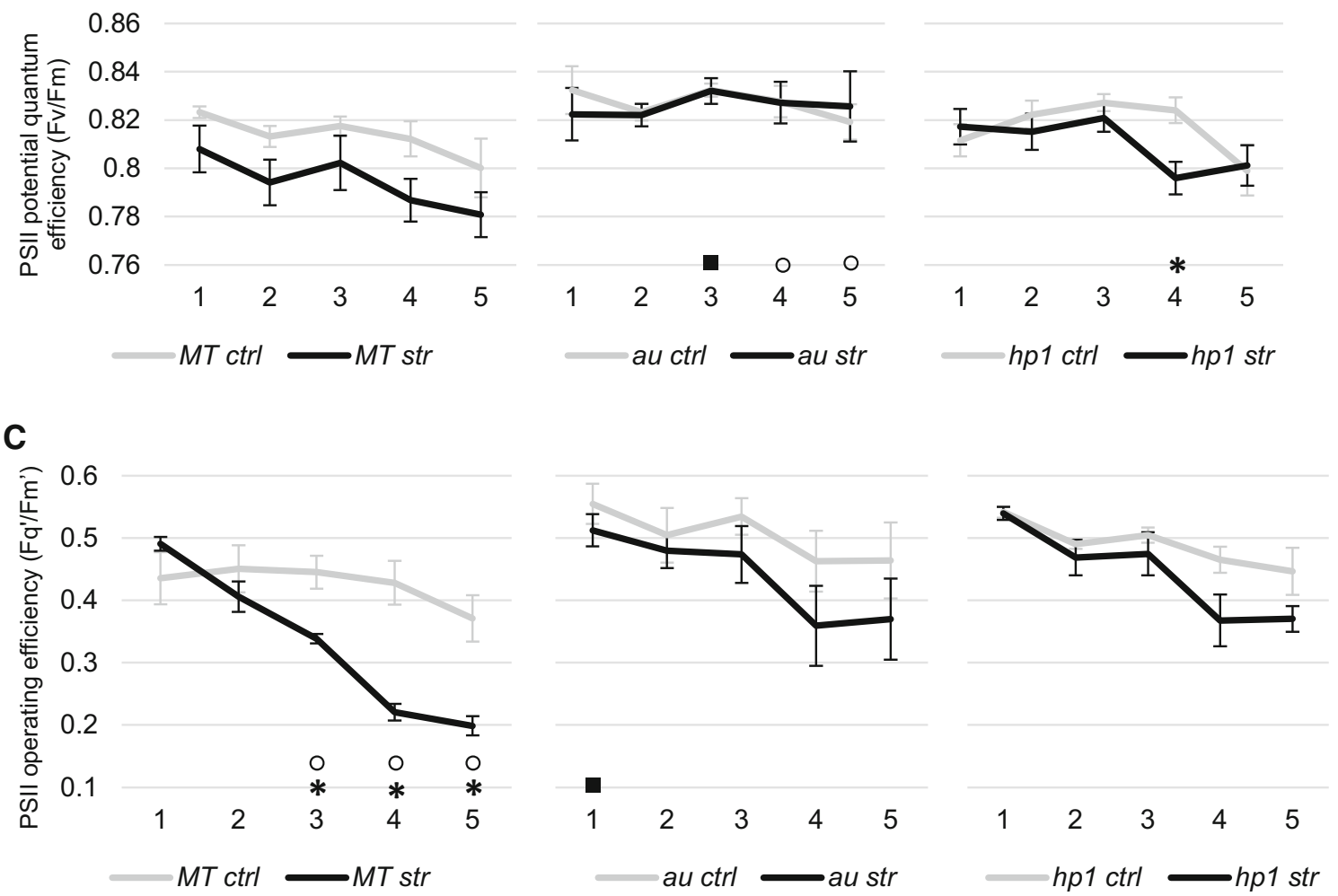

Fig. 3 Initial fluorescence (Fo) (a), PSII potential quantum efficiency $\left(F_{\mathrm{v}} / F_{\mathrm{m}}\right)(\mathbf{b})$ and PSII operating efficiency $\left(F_{\mathrm{q}}{ }^{\prime} / F_{\mathrm{m}}{ }^{\prime}\right)(\mathbf{c})$ of the leaves of the wild-type genotype (MT) and aurea (au) and high-pigment-1 ( hpl) mutants of tomato cv. Micro-Tom under normal water availability (ctrl gray line) or water withholding for 5 days (str black line). Bars indicate standard error, $n=5$. Each day of the experiment (on the horizontal axis) was compared separately. Different symbols

\section{Photosynthetic pigments}

The mutant $h p l$ had a higher content of chlorophyll $a$, chlorophyll $b$ and carotenoids than the other genotypes. Although the $a u$ mutant had the lowest values of chlorophyll $a$ and $b$, it had the highest chlorophyll $a: b$ ratio (Fig. 5). The water withholding treatment did not affect the content of chlorophylls and carotenoids in any genotype (Fig. 5). indicate significant differences (ANOVA followed by Tukey's test, $P<0.05)$. Asterisks were used for comparisons between the control and stress treatments within the same genotype, squares for comparisons among genotypes under the control treatment, and circles for comparisons among genotypes under the stress treatment. The absence of symbols indicates that no significant differences were found

\section{Malondialdehyde content and enzyme activity}

The water withholding treatment did not affect the leaf malondialdehyde content (MDA) of MT and $a u$, but $h p l$ plants under water withholding had lower MDA content than control individuals. Under normal water availability, $a u$ had lower MDA content compared to the other genotypes. In contrast, MT had the highest amount of MDA under water stress (Fig. 6a). 

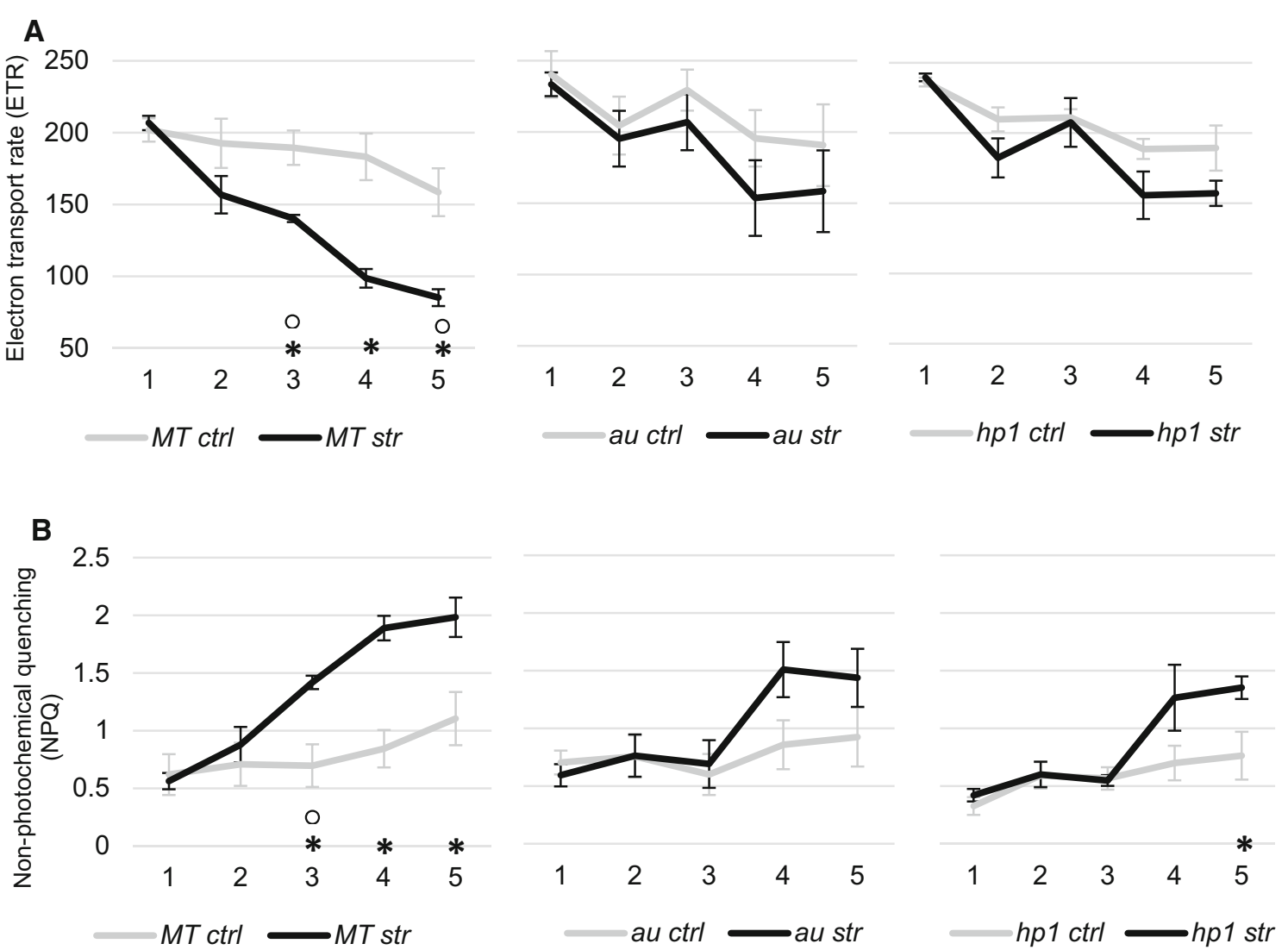

Fig. 4 Electron transport rate (ETR) (a) and non-photochemical quenching (NPQ) (b) of the leaves of the wild-type genotype (MT) and aurea (au) and high-pigment-1 ( hpl) mutants of tomato cv. Micro-Tom under normal water availability (ctrl gray line) or water withholding for 5 days (str black line). Bars indicate standard error, $n=5$. Each day of the experiment (on the horizontal axis) was

Under control conditions, all genotypes had the same enzyme activity for CAT, APX and SOD, but PAL and POX activities were higher in MT than in the mutants (Fig. 6b-e). Under water withholding conditions, CAT and APX activities were higher in $a u$, but SOD, PAL and POX activities were similar for all genotypes. Enzyme activity of the mutant $h p l$ was not affected by the water withholding treatment (Fig. 6b-e).

\section{Discussion}

Different studies relate that phytochromes affect the regulation of plant tolerance and/or susceptibility to abiotic stresses such as water deficiency. Evidences arose when it was known that far-red radiation, typically absorbed by phytochromes, induced decrease in stomatic conductance and xylem sap flow of cotton plants (Ouedraogo and Hubac 1982). Further studies found out that phytochrome-chromophore-deficient Nicotiana plumbaginifolia presented compared separately. Different symbols indicate significant differences (ANOVA followed by Tukey's test, $P<0.05$ ). Asterisks were used for comparisons between the control and stress treatments within the same genotype, and circles for comparisons among genotypes under the stress treatment. The absence of symbols indicates that no significant differences were found

high levels of abscisic acid (Kraepiel et al. 1994), hormone related to stress answers. Important parameters of water stress were studied in phytochrome-mutant plants: Dara-5, potato mutant that overexpress phyB, increased its stomatic conductance rates in $32 \%$ (Schittenhelm et al. 2004), high red:far-red radiation ratio induced an increase in active phyB in Arabidopsis, as well as in stomatic conductance and transpiration ratios (Boccalandro et al. 2009). Liu et al. (2012) indicate that phyB-deficient rice plants present less water loss and González et al. (2012) found out less stomatic conductance rates and less ABA sensibility in phyB-deficient Arabidopsis plants.

Unlike the previously described works, where the mutants were specific for a phytochrome family, in this present study, we found out that between phytochromedeficient (au) and high sensibility to phytochrome responses genotypes ( $h p 1)$, there was no difference regarding water potential decrease under water withholding conditions (Fig. 1), as well as few variations assigned to gas exchange parameters (Fig. 2). However, both 
Fig. 5 Photosynthetic pigments content chlorophyll $a$ (a), chlorophyll $b$ (b), chlorophyll $a: b$ ratio (c) and carotenoids (d) from leaves of the wild-type genotype (MT) and aurea (au) and high-pigment-1 (hpl) mutants of tomato cv. MicroTom under normal water availability (control) or water withholding for 5 days (stress). Bars indicate standard error, $n=4$. Different letters indicate significant differences (Tukey's test, $P<0.05)$. Upper case letters indicate comparisons between control and stress within the same genotype. Lower case letters indicate comparisons among genotypes under the same treatment (control or stress)

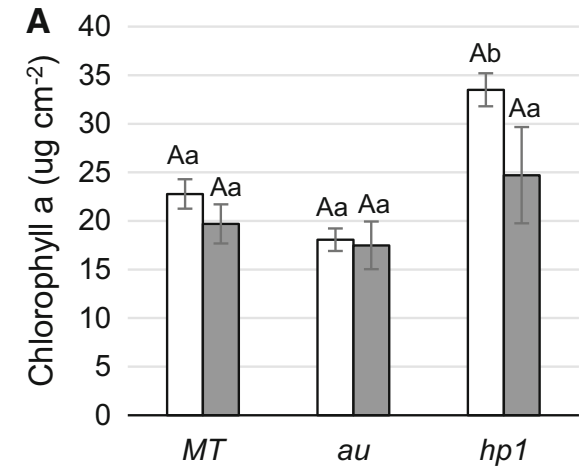

$\square$ Control $\square$ Stress

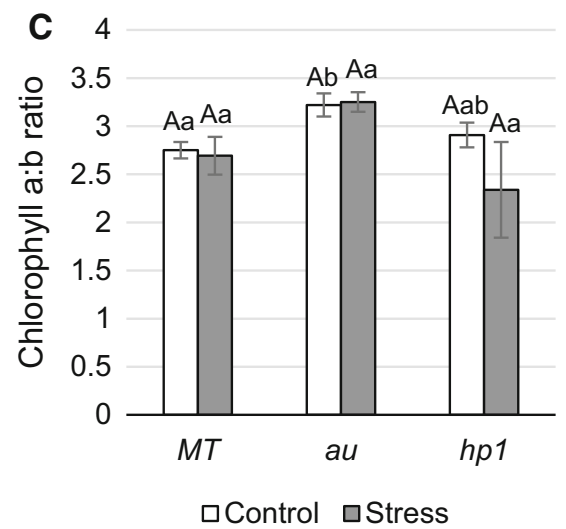

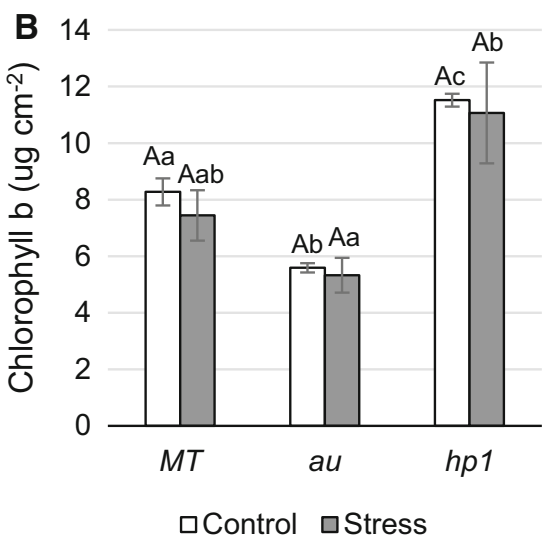

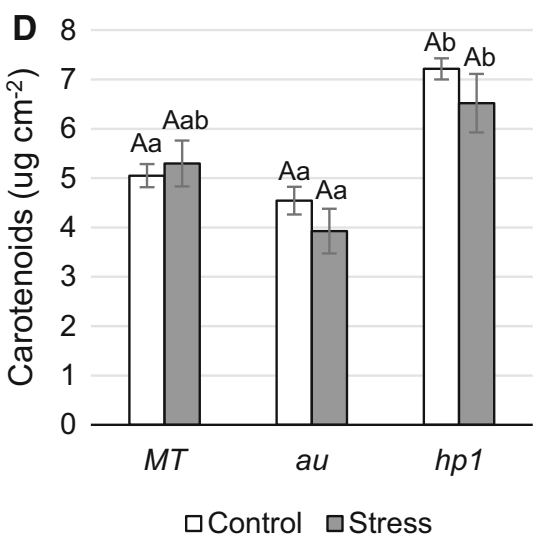

genotypes presented regular fluorescence parameters under water stress when compared to the wild-type (Figs. 3, 4). Such apparent stress tolerance of these mutant genotypes can be related to differential pigments composition (Fig. 5) and antioxidant enzymes activity (Fig. 6). The following discussion analyzes each one of these studied parameters in details, relating them to each other.

The decrease in water potential under water withholding conditions, along with the reduction of gas exchange rates and some changes of chlorophyll fluorescence parameters in tomato cv. Micro-Tom, confirm that this treatment was effective in creating stressful conditions. Changes in these parameters have been used in studies of many species under induced stress-like conditions (Miyashita et al. 2005; Rahbarian et al. 2011; Benesová et al. 2012), including photomorphogenic mutants (Biehler et al. 1997; Boggs et al. 2010; Carvalho et al. 2011a; Liu et al. 2012).

Under water stress, $a u, h p l$ and MT plants had lower water potential (Fig. 1) and reduced rates of stomatal conductance and transpiration from the fourth day of experiment on (Fig. 2b, c). As a consequence, it is likely that the diffusion of $\mathrm{CO}_{2}$ to the mesophyll became limited, restraining RUBISCO activity and promoting a decrease in photosynthetic rate (Fig. 2a). A similar reduction in gas exchange rates due to water withholding was also recorded in other species (Lawlor and Tezara 2009; Carvalho et al. 2011a; González et al. 2012).

Intriguingly, although it has been shown that phytochromes may strongly modulate adverse water stress responses in tomato (Auge et al. 2012; D’Amico-Damião et al. 2015), the phytochrome-deficiency mutant seems not to alter its water relations under water deficit condition (Figs. 1, 2). In fact, although $a u$ fails to maintain the transpiration rhythmicity (Sokolskaya et al. 2003), this mutant showed no change in its rate of transpiration during water stress (Biehler et al. 1997). It is essential to comment that the $a u$ mutation is complex. In this mutant, the phytochrome is barely detected at the seedling stage (Terry and Kendrick 1996), but up to $70 \%$ of holophytochrome is restablished at the mature-fruit stage (López-Juez et al. 1990). This fact results in a chlorotic and etiolated plant, but curiously photosynthesis rate is found to be similar to MT (Fig. 2) (Biehler et al. 1997). Thus, if phytochromedeficiency change water relations in $a u$, a more detailed analysis of this particular aspect needs to be carried out.

On the other hand, $h p l$ mutant showed enhanced transpiration (Fig. 2c). Carvalho et al. (2011a) showed that the altered transpiration in $h p l$ seems to occur also under well- 
Fig. 6 Malondialdehyde content (MDA) (a) and enzyme activity (EA) of catalase (CAT) (b), ascorbate peroxidase (APX) (c), superoxide dismutase (SOD) (d), phenylalanine ammonia lyase (e) and peroxidase (POX) (f) from leaves of the wild-type genotype (MT) and aurea (au) and highpigment-1 ( $\mathrm{hpl}$ ) mutants of tomato cv. Micro-Tom under normal water availability (control) and under water withholding for 5 days (stress). Bars indicate standard deviation, $n=4$. Different letters indicate significant differences (Tukey's test, $P<0.05)$. Upper case letters indicate comparisons between control and stress within the same genotype. Lower case letters indicate comparisons among genotypes under the same treatment (control or stress)
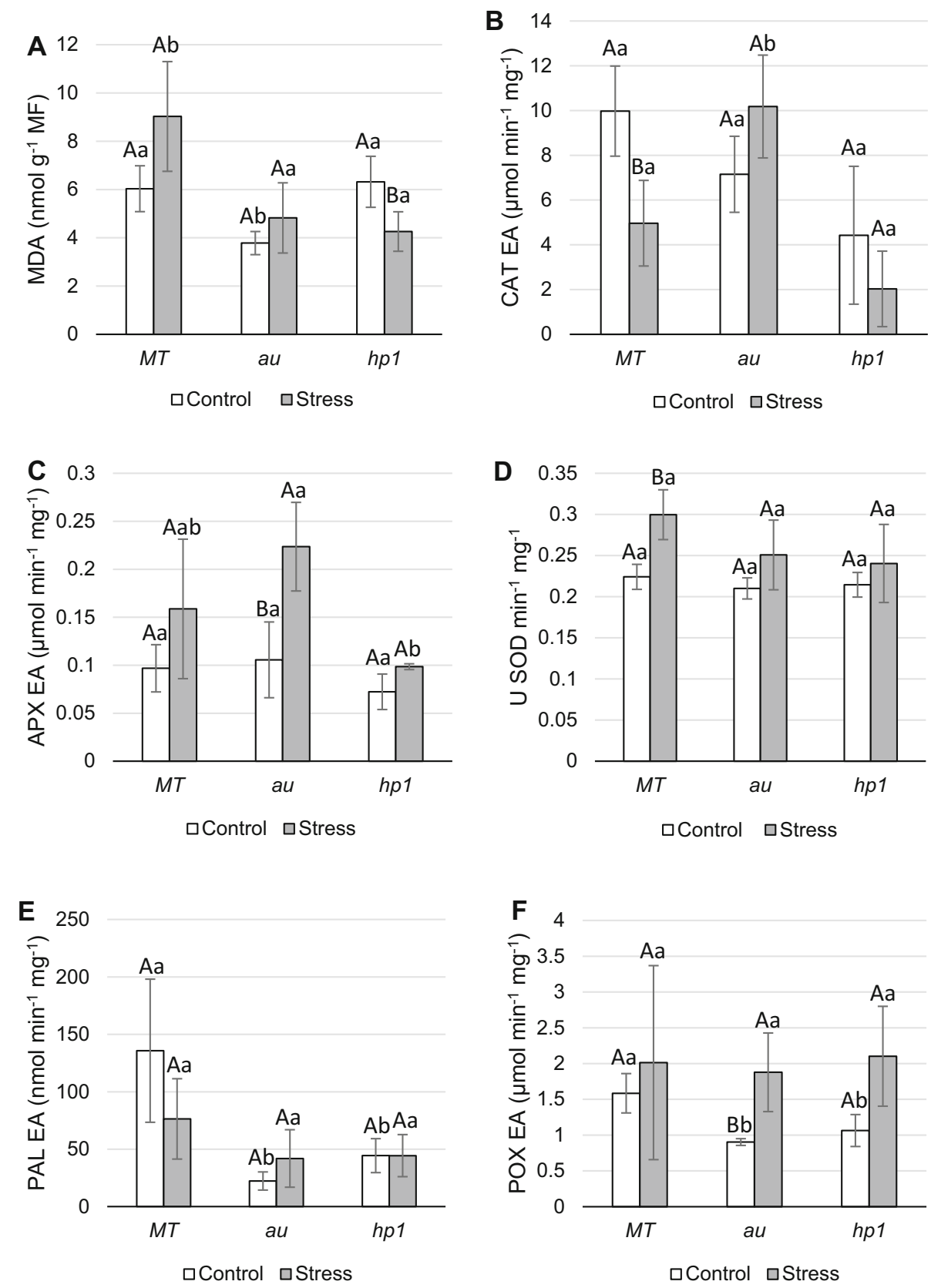

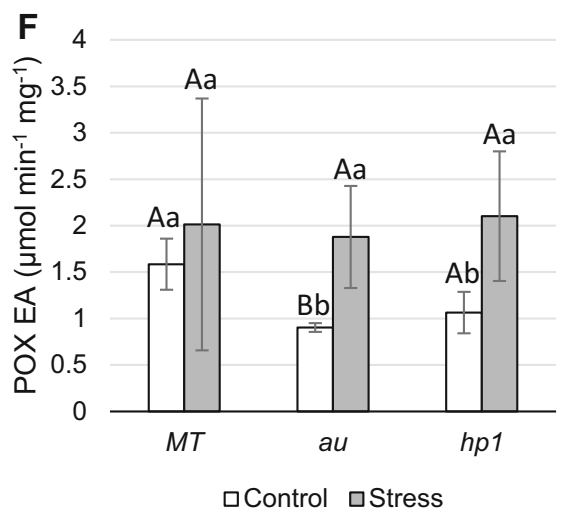

hydrated condition. Although in this condition we showed that MT and $h p l$ had a similar transpiration rate, it is evident that this mutant has a high evaporative demand, but it works through a complex physiological mechanism since its water potential (Fig. 1) and water use efficiency (Carvalho et al. 2011a) do not change. Such complexity is being unraveled with the recognition that the transcript levels for ABA biosynthetic genes were down-regulated in $h p l$ (Kilambi et al. 2013), which can be associated to enhanced transpiration in this mutant. However, stomatal conductance of $h p l$ does not differ from MT, making the interaction between $\mathrm{ABA}$ changes and $h p l$ a trending issue to be explored.
Photosynthetic rates were statistically the same for the three genotypes in the control treatment. However, under water withholding the photosynthetic rate of $a u$ only decreased on the fifth day, while in the other genotypes a significant drop was observed on the fourth day (Fig. 2a). This is an interesting photosynthetic response, because $a u$ is the genotype with the lowest content of chlorophyll and carotenoids (Fig. 5). Melo et al. (2009) also noticed the similarity in potential photosynthetic rates between the wild-type genotype and the $a u$ mutant, despite the pigment deficiency in $a u$. Other factors may allow this mutant to overcome the pigment impairment, such as higher nitrogen allocation and protein content in $a u$ compared to the wild- 
type (López-Juez et al. 1990; Melo et al. 2009), contributing to increase the amount of proteins that are important for carboxylation and other stages of the photosynthetic process.

Chlorophyll fluorescence parameters provide useful data for estimating, in a non-invasive way, the potential and operating quantum efficiencies of PSII photochemistry, linking them to carbon assimilation (Genty et al. 1989). These parameters may be used as indicators to compare the metabolic and energetic balance of photosynthesis between cultivars and mutant genotypes under water stress ( $\mathrm{Li}$ et al. 2006; Rahbarian et al. 2011; Mishra et al. 2012).

The $a u$ mutant had the lowest chlorophyll $a$ content (Fig. 5), although it was statistically similar to MT, and the lowest Fo values (Fig. 3a). Despite the fact that $h p l$ had higher chlorophyll content (Fig. 5), its Fo did not differ from MT (Fig. 3a). The water withholding treatment had no effect on the pigment content, thus Fo values were not affected by the experimental conditions.

The $F_{\mathrm{v}} / F_{\mathrm{m}}$ ratio estimates the maximum quantum efficiency of PSII photochemistry (Butler 1978). This parameter has been widely used to detect disturbance of the photosynthetic apparatus induced by stress, since photodamage to the reaction centers can decrease the values of $F_{\mathrm{v}} / F_{\mathrm{m}}$ (Baker and Rosenqvist 2004). The water withholding treatment had no impact on the potential quantum efficiency of any of the genotypes analyzed (Fig. 3b). Since Fo and $F_{\mathrm{v}} / F_{\mathrm{m}}$ are determined primarily by chlorophyll content, the water withholding treatment had no impact on these parameters. In other species, such as potato (Jefferies 1994), coffee (Lima et al. 2002), wheat (Lu and Zhang 1999) and grape (Wang et al. 2012), drought did not cause variation of the $F_{\mathrm{v}} / F_{\mathrm{m}}$ ratio either. On the other hand, on the fourth and fifth days of water withholding experiment, $F_{\mathrm{v}} / F_{\mathrm{m}}$ was higher in $a u$ than in MT and $h p l$ (Fig. 3b).

In MT, both PSII operating efficiency (Fig. 3c) and electron transport rate (Fig. 4a) were inhibited, while nonphotochemical quenching increased (Fig. 4b). Based on these results, we can infer that stomatal limitations of photosynthesis decreased the consumption of ATP and $\mathrm{NADPH}$, attenuating the electron transport rate and, as consequence, the $F_{\mathrm{q}}{ }^{\prime} / F_{\mathrm{m}}{ }^{\prime}$ ratio (Baker and Rosenqvist 2004). Both $\mathrm{CO}_{2}$ deficiency and RUBISCO inhibition reduce the NADPH oxidation rate in Calvin's cycle. Therefore, the primary electron acceptor $\mathrm{NADP}^{+}$is not sufficiently available. Water stress conditions, combined with continuous exposition to light, may result in overreduction of the ETC and damages to the photosynthetic apparatus (Aro et al. 1993; Reddy et al. 2004; Schöttler and Tóth 2014).

There were no differences between control and treatment for $a u$ and $h p l$ with relation to Fq'/Fm', ETR and
NPQ (Figs. 3c, 4a, b), indicating that other mechanisms for energy dissipation were running efficiently (as stated below). Biehler et al. (1997) demonstrated that $a u$ was able to keep the normal functioning of the electron transport chain, despite a decrease in the photosynthetic rate, due to its higher capacity to keep electron acceptors free, lowering the potential to store its reduced equivalents.

The yellow color of $a u$ leaves limits the absorption of light radiation by the photosystems, which are proportionally less excited and are able to keep the ETC functioning adequately even under the limiting $\mathrm{CO}_{2}$ conditions caused by water stress (Fig. 4a). Biehler et al. (1997) pointed out that, compared to the leaves of the wild-type genotype, $35 \%$ of the radiation reaching au leaves is reflected. Becker et al. (1992) argue that the lower chlorophyll $b$ content associated with the PSII (Fig. 5b) decreases its capacity to harvest light, preventing overexcitation of the pigments while keeping the quantum yield unaffected.

Haupt-Herting and Fock (2000) demonstrated that tomato plants under water stress considerably increase the emission of energy as heat and inhibit PSII activity in order to avoid damage to the photosynthetic apparatus, which is consistent with the data presented here for MT (Figs. 3c, $4 b)$. Moreover, these authors verified that oxygen was used as an alternative electron acceptor in an attempt to keep ETC running, as observed by Biehler et al. (1997) for the wild-type genotype, which increased $\mathrm{O}_{2}$ reduction rates. The electron acceptance and consequent incomplete oxidation of oxygen can generate reactive oxygen species (ROS), directly affecting the photosynthetic process (Bartosz 1997; Gill and Tuteja 2010).

Under water withholding, MT had higher MDA content (Fig. 6a), indicating higher lipid peroxidation and, consequently, greater damage to the membranes due to the action of ROS. Therefore, MT presented low PSII operating efficiency (Fig. 3c) and low ETR (Fig. 4a) under these conditions. The lower MDA content registered for $a u$ and $h p l$ indicates that the mutants have greater potential to protect themselves against the oxidative stress damages that result from stressful water withholding conditions.

Under normal water availability, MT had higher activities of PAL, which is essential for the synthesis of many antioxidant phenylpropanoids (Jones 1984), and POX, a defense against hydrogen peroxide (Siegel 1993). However, under water withholding conditions, these enzyme activities were the same for all genotypes (Fig. 6e, f).

The $a u$ mutant kept the ETR running and the PSII under normal operation despite the photosynthetic limitations imposed by water withholding (Figs. 3c, 4a), possibly by increasing the activity of antioxidant enzymes such as CAT, POX and APX (Fig. 6b, c, e). The lower impact of ROS over the metabolism of this mutant can be verified by 
its low MDA content, also observed by Monteiro et al. (2012). Biehler et al. (1997) also found that $a u$ oxygen reduction rates did not increase under water stress. Although the chlorophyll $a$ content of $a u$ was low, its carotenoid levels were similar to the levels in MT (Fig. 5), which may improve the capacity to quench the excess energy caused by chlorophyll excitation, resulting in less damage to the photosystems.

Similar to $a u, h p l$ did not decrease its ETR, and its photochemical yield was not affected by the water withholding conditions (Figs. 3c, 4a). However, despite the fact that the antioxidant enzyme activity was not higher, a low MDA content was recorded (Fig. 6). Monteiro et al. (2012) suggested that, under normal conditions, $h p l$ has lower antioxidant enzyme activity when compared to MT, but that under stress conditions, the mutant responses may be exaggerated due to its hypersensitivity to light-dependent processes. This hypothesis, however, was not corroborated under the water withholding conditions established in this study.

The mutant $h p l$ had the highest carotenoid content (Fig. 5d), which helps to decrease ROS generation due to chlorophyll excitation and energy dissipation through nonphotochemical processes (Eberhard et al. 2008). The NPQ levels increased on the fifth day of the experiment under water withholding conditions (Fig. 4b). Therefore, carotenoids may play an essential role in maintaining the normal functioning of the photosystems in $h p l$, even under stressful water withholding conditions.

It is possible that genotypes with higher amounts of antioxidants and products derived from the phenylpropanoid metabolism, such as the hpl mutant, are also less vulnerable to water stress and, as a consequence, PAL activity does not change in the short term because they already hold enough biochemical defenses against oxidative stress. Phimchan et al. (2014) observed that hot pepper cultivars rich in capsaicinoid compounds, derived from the phenylpropanoid metabolism, suffered no alteration of PAL activity and were less susceptible to water stress compared to cultivars with lower amounts of capsaicinoids.

We conclude that, considering the higher PSII operating efficiency and ETR during the water withholding treatment, tomato photomorphogenic mutants $a u$ and $h p l$ present higher tolerance to water stress when compared to the wild-type MT. Some evidence shows that light, operating via the phytochrome, is connected to the regulation of antioxidant enzyme activity (Drumm and Schopfer 1974; Zhong et al. 1994, 1997; Mullineaux et al. 2000) and to the biosynthesis of antioxidant compounds, including carotenoids and phenolic compounds (Pizarro and Stange 2009; Toledo-Ortiz et al. 2010; Dias et al. 2015). Therefore, the tolerance of mutants to the effects of water withholding may be explained by the higher activity of antioxidant enzymes, such as CAT and APX, in $a u$ and by a higher concentration of antioxidant compounds, such as carotenoids, in $h p l$. However, additional studies are needed to corroborate these hypotheses.

Author contribution statement FRRA carried out the research during his Master Degree course responsible for the experiment running, data collection and analyses as well as the writing of the manuscript. AJCF was responsible for the plant cultivation in the greenhouse, and worked with FRRA on the IRGA and fluorescence analyses and data synthesis. HCM helped with the data review, experiment design and critical review of the manuscript. ACC runs the lab where the plants were grown and where the analyses were done collaborating with equipments and reagents needed, as well as the critical review of the manuscript. KJTN supervised and helped with the antioxidant analyses. RFC reviewed the manuscript and helped to structure the introduction and the discussion of the present work.

Acknowledgments The first author would like to thank the Fundação de Amparo à Pesquisa do Estado de Goiás (FAPEG) for the Master's Program Scholarship granted (Call 03/13).

\section{References}

Ahmad P, Jaleel CA, Salem MA, Nabi G, Sharma S (2010) Roles of enzymatic and non-enzymatic antioxidants in plants during abiotic stress. Crit Rev Biotechnol 30:161-175. doi:10.3109/ 07388550903524243

Aro EM, Virgin I, Andersson B (1993) Photoinhibition of photosystem II: inactivation, protein damage and turnover. Biochim Biophys Acta Bioenerg 1143: 113-134. doi:10.1016/00052728(93)90134-2

Auge GA, Rugnone ML, Cortés LE, González CV, Zarlavsky G, Boccalandro HE, Sánchez RA (2012) Phytochrome A increases tolerance to high evaporative demand. Physiol Plantarum 146:228-235. doi:10.1111/j.1399-3054.2012.01625.X

Azevedo RA, Alas RM, Smith RJ, Lea PJ (1998) Response of antioxidant enzymes to transfer from elevated carbon dioxide to air and ozone fumigation, in the leaves and roots of wild-type and a catalase-deficient mutant of barley. Physiol Plantarum 104:280-292. doi:10.1034/j.1399-3054.1998.1040217.x

Baker NR (2008) Chlorophyll fluorescence: a probe of photosynthesis in vivo. Ann Rev Plant Biol 59:89-113. doi:10.1146/annurev. arplant.59.032607.092759

Baker NR, Rosenqvist E (2004) Applications of chlorophyll fluorescence can improve crop production strategies: an examination of future possibilities. J Exp Bot 55:1607-1621. doi:10.1093/jxb/ erh196

Bartosz G (1997) Oxidative stress in plants. Acta Physiol Plantarum 19:47-64. doi:10.1007/s11738-997-0022-9

Becker TW, Foyer C, Caboche M (1992) Light-regulated expression of the nitrate-reductase and nitrite-reductase genes in tomato and in the phytochrome-deficient aurea mutant of tomato. Planta 188:39-47. doi:10.1007/BF00198937

Benesová M, Holá D, Fischer L, Jedelský PL, Hnilicka F, Wilhelmová N, Rothová O, Kocová M, Procházková D, Honnerová J, Fridrichová L, Hnilicková H (2012) The physiology and 
proteomics of drought tolerance in maize: early stomatal closure as a cause of lower tolerance to short-term dehydration? PLoS One 7:e38017. doi:10.1371/journal.pone.0038017

Biehler K, Haupt S, Beckmann J, Fock H, Becker TW (1997) Simultaneous $\mathrm{CO}_{2^{-}}$and ${ }^{16} \mathrm{O}_{2} /{ }^{18} \mathrm{O}_{2}$-gas exchange and fluorescence measurements indicate differences in light energy dissipation between the wild type and the phytochrome-deficient aurea mutant of tomato during water stress. J Exp Bot 48:1439-1449. doi:10.1093/jxb/48.7.1439

Bilger W, Björkman O (1990) Role of xantophyll cycle in photoprotection elucidated by measurements of light-induced absorbance changes, fluorescence and photosynthesis in leaves of Hedera canariensis. Photosynth Res 25:173-185. doi:10.1007/BF0003 3159

Bilger W, Schreiber U, Bock M (1995) Determination of the quantum efficiency of photosystem II ana of non-photochemical quenching of chlorophyll fluorescence in the field. Oecologia 102:425-432. doi:10.1007/BF00341354

Boccalandro HE, Ploschuk EL, Yanovsky MJ, Sánchez RA, Gatz C, Casal JJ (2003) Increased phytochrome B alleviates density effects on tuber yield of field potato crops. Plant Physiol 133:1539-1546. doi:10.1104/pp.103.029579

Boccalandro HE, Rugnone ML, Moreno JE, Ploschuk EL, Serna L, Yanovsky MJ, Casal JJ (2009) Phytochrome B enhances photosynthesis at the expense of water-use efficiency in Arabidopsis. Plant Physiol 150:1083-1092. doi:10.1104/pp.109. 135509

Boggs JZ, Loewy K, Bibee K, Heschel MS (2010) Phytochromes influence stomatal conductance plasticity in Arabidopsis thaliana. Plant Growth Regul 60:77-81. doi:10.1007/s10725-0099427-3

Bradford MM (1976) A rapid and sensitive method for the quantitation of microgram quantities of protein utilizing the principle of protein-dye binding. Anal Biochem 72:248-254. doi:10.1016/0003-2697(76)90527-3

Butler WL (1978) Energy distribution in the photochemical apparatus of photosynthesis. Ann Rev Plant Physiol 29:345-378. doi:10. 1146/annurev.pp.29.060178.002021

Carvalho RF, Aidar ST, Azevedo RA, Dodd IC, Peres LEP (2011a) Enhanced transpiration rate in the high pigment 1 tomato mutant and its physiological significance. Plant Biol 13:546-550. doi:10.1111/j.1438-8677.2010.00438.x

Carvalho RF, Campos ML, Azevedo RA (2011b) The role of phytochrome in stress tolerance. J Integr Plant Biol 53:920-929. doi:10.1111/j.1744-7909.2011.01081.x

Casal JJ, Ballaré CL, Tourn M, Sánchez RA (1994) Anatomy, growth and survival of a long-hypocotyl mutant of Cucumis sativus deficient in phytochrome B. Ann Bot 73:569-575. doi:10.1006/ anbo.1994.1071

Castillon A, Shen H, Huq E (2007) Phytochrome interacting factors: central players in phytochrome-mediated light signaling networks. Trends Plant Sci 12:514-521. doi:10.1016/j.tplants.2007. 10.001

Chance B, Maehly AC (1955) Assay of catalases and peroxidases. Methods Enzymol 2:764-775

D’Amico-Damião V, Cruz FJR, Gavassi MA, Santos DMM, Melo HC, Carvalho RF (2015) Photomorphogenic modulation of water stress in tomato (Solanum lycopersicum L.): the role of phytochromes A, B1 and B2. J Hort Sci Biotechnol 90:25-30

Dias T, Melo HC, Alves FRR, Carvalho RF, Carneiro KS, Sousa CM (2015) Compostos fenólicos e capacidade antioxidante em frutos de tomateiros mutantes fotomorfogenéticos. Ciênc Rural 45:782-787. doi:10.1590/0103-8478cr20140098

Drumm H, Schopfer P (1974) Effect of phytochrome on development of catalase activity and isoenzyme pattern in mustard (Sinapis alba L.) seedlings. Planta 120:13-30. doi:10.1007/BF00388268
Eberhard S, Finazzi G, Wollman F (2008) The dynamics of photosynthesis. Ann Rev Genet 42:463-515. doi:10.1146/ annurev.genet.42.110807.091452

Ehleringer J (1981) Leaf absorptances of Mohave and Sonoran desert plants. Oecologia 49:366-370

Genty B, Briantais J, Baker NR (1989) The relationship between the quantum yield of photosynthetic electron transport and quenching of chlorophyll fluorescence. Biochim Biophys Acta 990:87-92. doi:10.1016/S0304-4165(89)80016-9

Giannopolitis CN, Ries SK (1977) Superoxide dismutases I. Occurrence in higher plants. Plant Physiol 59:309-314. doi:10.1104/ pp.59.2.309

Gill SS, Tuteja N (2010) Reactive oxygen species and antioxidant machinery in abiotic stress tolerance in crop plants. Plant Physiol Biochem 48:909-930. doi:10.1016/j.plaphy.2010.08.016

González CV, Ibarra SE, Piccoli PN, Botto JF, Boccalandro HE (2012) Phytochrome B increases drought tolerance by enhancing ABA sensitivity in Arabidopsis thaliana. Plant Cell Environ 35:1958-1968. doi:10.1111/j.1365-3040.2012.02529.x

Haupt-Herting S, Fock HP (2000) Exchange of oxygen and its role in energy dissipation during drought stress in tomato plants. Physiol Plantarum 110:489-495. doi:10.1111/j.1399-3054.2000. 1100410.x

Havir EA, McHale NA (1987) Biochemical and developmental characterization of multiple forms of catalase in tobacco leaves. Plant Physiol 84:450-455. doi:10.1104/pp.84.2.450

Heath RL, Packer L (1968) Photoperoxidation in isolated chloroplasts I. Kinetics and stoichiometry of fatty acid peroxidation. Arch Biochem Biophys 125:189-198. doi:10.1016/0003-9861(68) 90654-1

Hughes J (2010) Phytochrome three-dimensional structures and functions. Biochem Soc T 38:710-716. doi:10.1042/BST0380710

Jefferies RA (1994) Drought and chlorophyll fluorescence in fieldgrown potato (Solanum tuberosum). Physiol Plantarum 90:93-97. doi:10.1111/j.1399-3054.1994.tb02197.x

Jones DH (1984) Phenyalanine ammonia-lyase: regulation of its induction and its role in plant development. Phytochem 23:1349-1359. doi:10.1016/S0031-9422(00)80465-3

Kar M, Mishra D (1976) Catalase, peroxidase and polyphenoloxidase activities during rice leaf senescence. Plant Physiol 57:315-319. doi:10.1104/pp.57.2.315

Kendrick RE, Kerckhoffs LHJ, Van Tuinen A, Koornneef M (1997) Photomorphogenic mutants of tomato. Plant Cell Environ 20:746-751. doi:10.1046/j.1365-3040.1997.d01-109.x

Kilambi HV, Kumar R, Sharma R, Sreelakshmi Y (2013) Chromoplast-specific carotenoid-associated protein appears to be important for enhanced accumulation of carotenoids in $\mathrm{hp} 1$ tomato fruits. Plant Physiol 161:2085-2101. doi:10.1104/pp.112.212191

Kraepiel Y, Rousselin P, Sotta B, Kerhoas L, Einhorn J, Caboche M, Miginiac E (1994) Analysis of phytochrome- and ABA-deficient mutants suggests that ABA degradation is controlled by light in Nicotiana plumbaginifolia. Plant J 6:665-672. doi:10.1046/j. 1365-313X.1994.6050665.x

Laisk A, Loreto F (1996) Determining photosynthetic parameters from leaf $\mathrm{CO}_{2}$ exchange and chlorophyll fluorescence. Plant Physiol 110:903-912

Lawlor DW, Tezara W (2009) Causes of decreased photosynthetic rate and metabolic capacity in water-deficient leaf cells: a critical evaluation of mechanisms and integration of processes. Ann Bot 103:561-579. doi:10.1093/aob/mcn244

Li RH, Guo PG, Baum M, Grando S, Ceccarelli S (2006) Evaluation of chlorophyll content and fluorescence parameters as indicators of drought tolerance in barley. Agric Sci China 5:751-757. doi:10.1016/S1671-2927(06)60120-X

Lima ALS, Da Matta FM, Pinheiro HA, Totola MR, Loureiro ME (2002) Photochemical responses and oxidative stress in two 
clones of Coffea canephora under water deficit conditions. Environ Exp Bot 47:239-247. doi:10.1016/S0098-8472(01) 00130-7

Liu Y, Roof S, Ye Z, Barry C, Van Tuinen A, Vrebalov J, Bowler C, Giovannoni J (2004) Manipulation of light signal transduction as a means of modifying fruit nutritional quality in tomato. Proc Natl Acad Sci USA 101:9897-9902. doi:10.1073/pnas.0400935101

Liu J, Zhang F, Zhou J, Chen F, Wang B, Xie X (2012) Phytochrome B control of total leaf area and stomatal density affects drought tolerance in rice. Plant Mol Biol 78:289-300. doi:10.1007/ s11103-011-9860-3

López-Juez E, Nagatani A, Buurmeijer WF, Peters JL, Furuya M, Kendrick RE, Wesselius JC (1990) Response of light-grown wild-type and aurea-mutant tomato plants to end-of-day far-red light. J Photochem Photobiol B: Biol 4:391-405. doi:10.1016/ 1011-1344(90)85018-R

Lu C, Zhang J (1999) Effects of water stress on photosystem II photochemistry and its thermostability in wheat plants. J Exp Bot 50:1199-1206. doi:10.1093/jxb/50.336.1199

Melo HC, Castro EM, Soares AM, Oliveira C, Ramos SJ (2009) Características fisiológicas de microtomateiros fitocromo-mutantes. Ciênc Agrotec 33:1213-1219. doi:10.1590/S141370542009000500003

Mishra KB, Iannacone R, Petrozza A, Mishra A, Armentano N, La Vecchia G, Trtílek M, Cellini F, Nedbal L (2012) Engineered drought tolerance in tomato plants is reflected in chlorophyll fluorescence emission. Plant Sci 182:79-86. doi:10.1016/j. plantsci.2011.03.022

Miyashita K, Tanakamaru S, Maitani T, Kimura K (2005) Recovery responses of photosynthesis, transpiration and stomatal conductance in kidney bean following drought stress. Environ Exp Bot 53:205-214. doi:10.1016/j.envexpbot.2004.03.015

Mohr H, Drumm H, Schmidt R, Steinitz B (1979) The effect of light pretreatments on phytochrome-mediated induction of anthocyanin and of phenyalanine ammonia-lyase. Planta 146:369-376. doi:10.1007/BF00387810

Monteiro CC, Rolão MB, Franco MR, Peters LP, Cia MC, Capaldi FR, Carvalho RF, Gratão PL, Rossi ML, Martinelli AP, Peters LEP, Azevedo RA (2012) Biochemical and histological characterization of tomato mutants. An Acad Bras Ciênc 84:573-585. doi:10.1590/S0001-37652012005000022

Mullineaux P, Ball L, Escobar C, Karpinska B, Creissen G, Karpinski S (2000) Are diverse signalling pathways integrated in the regulation of Arabidopsis antioxidant defence gene expression in response to excess excitation energy? Philos Trans R Soc London, Ser B 355:1531-1540. doi:10.1098/rstb.2000.0713

Muramoto T, Kami C, Kataoka H, Iwata N, Linley PJ, Mukougawa K, Yokota A, Kohchi T (2005) The tomato photomorphogenetic mutant aurea is deficient in phytochromobilin synthase for phytochrome chromophore biosynthesis. Plant Cell Physiol 46:661-665. doi:10.1093/pcp/pci062

Murshed R, Lopez-Lauri F, Sallanon H (2013) Effects of water stress on antioxidant systems and oxidative parameters in fruits of tomato (Solanum lycopersicum L. cv. Micro-Tom). Physiol Mol Biol Plants 19:363-378. doi:10.1007/s12298-013-0173-7

Nakano Y, Asada K (1981) Hydrogen peroxide is scavenged by ascorbate-specific peroxidase in spinach chloroplasts. Plant Cell Physiol 22:867-880

Noctor G, Foyer CH (1998) Ascorbate and gluthatione: keeping active oxygen under control. Ann Rev Plant Physiol Plant Mol Biol 49:249-279. doi:10.1146/annurev.arplant.49.1.249

Ouedraogo M, Hubac C (1982) Effect of far red light on drought resistance of cotton. Plant Cell Physiol 23:1297-1303

Phimchan P, Chanthai S, Bosland PW, Techawongstien S (2014) Enzymatic changes in phenylalanine ammonia-lyase, cinnamic4-hydroxylase, capsaicin synthase and peroxidase activities in
Capsicum under drought stress. J Agric Food Chem 62:7057-7062. doi:10.1021/jf4051717

Pizarro L, Stange C (2009) Light-dependent regulation of carotenoid biosynthesis in plants. Cienc Investig Agrar 36:143-162. doi:10. 4067/S0718-16202009000200001

Rahbarian R, Khavari-Nejad R, Ganjeali A, Bagheri A, Najafi F (2011) Drought stress effects on photosynthesis, chlorophyll fluorescence and water relations in tolerant and susceptible chickpea (Cicer arietinum L.) genotypes. Acta Biol Cracoviensia Ser Bot 53:47-56. doi:10.2478/v10182-011-0007-2

Rascher U, Liebig M, Lüttge U (2000) Evaluation of instant lightresponse curves of chlorophyll fluorescence parameters obtained with a portable chlorophyll fluorometer on site in the field. Plant, Cell Environ 23:1397-1405. doi:10.1046/j.1365-3040.2000. 00650.x

Reddy AR, Chaitanya KV, Vivekanandan M (2004) Drought-induced responses of photosynthesis and antioxidant metabolism in higher plants. J Plant Physiol 161:1189-1202. doi:10.1016/j. jplph.2004.01.013

Schittenhelm S, Menge-Hartmann U, Oldenburg E (2004) Photosynthesis, carbohydrate metabolism and yield of phytochrome-Boverexpressing potatoes under different light regimes. Crop Sci 44:131-143. doi: $10.2135 /$ cropsci2004.1310

Schopfer P (1977) Phytochrome control of enzymes. Annu Rev Plant Physiol 28:223-252. doi:10.1146/annurev.pp.28.060177.001255

Schöttler MA, Tóth SZ (2014) Photosynthetic complex stoichiometry dynamics in higher plants: environmental acclimation and photosynthetic flux control. Front Plant Sci 5:188. doi:10.3389/ fpls.2014.00188

Sharma R, Sopory SK, Guha-Mukherjee S (1976) Phytochrome regulation of peroxidase activity in maize. Plant Sci Lett 6:69-75. doi:10.1016/0304-4211(76)90181-4

Siegel BZ (1993) Plant peroxidases: an organismic perspective. Plant Growth Regul 12:303-312. doi:10.1007/BF00027212

Silva FB, Costa AC, Alves RRP, Megguer CA (2014) Chlorophyll fluorescence as an indicator of cellular damage by glyphosate herbicide in Raphanus sativus L. plants. Am J Plant Sci 5:2509-2519. doi:10.4236/aips.2014.516265

Smirnoff N (1993) The role of active oxygen in the response of plants to water deficit and desiccation. New Phytol 125:27-58. doi:10. 1111/j.1469-8137.1993.tb03863.x

Sokolskaya SV, Sveshnikova NV, Kochetova GV, Solovchenko AE, Gostimski SA, Bashtanova OB (2003) Involvement of phytochrome in regulation of transpiration: red-/far red-induced responses in the chlorophyll-deficient mutant of pea. Func Plant Biol 30:1249-1259. doi:10.1104/pp.112.212191

Terry MJ, Kendrick RE (1996) The aurea and yellow-green-2 mutants of tomato are deficient in phytochrome chromophore synthesis. J Biol Chem 271:21681-21686. doi:10.1074/jbc.271.35.21681

Thomsen B, Drumm-Herrel H, Mohr H (1992) Control of the appearance of ascorbate peroxidase (EC 1.11.1.11) in mustard seedling cotyledons by phytochrome and photooxidative treatments. Planta 186:600-608. doi:10.1007/BF00198042

Toledo-Ortiz G, Huq E, Rodríguez-Concepción M (2010) Direct regulation of phytoene synthase gene expression and carotenoid biosynthesis by phytochrome-interacting factors. Proc Natl Acad Sci USA 107:11626-11631. doi:10.1073/pnas.0914428107

Wang FF, Lian HL, Kang CY, Yang HQ (2010) Phytochrome B is involved in mediating red light-induced stomatal opening in Arabidopsis thaliana. Mol Plant 3:246-259. doi:10.1093/mp/ ssp097

Wang ZX, Chen L, Ai J, Qin HY, Liu YX, Xu PL, Jiao ZQ, Zhao Y, Zhang QT (2012) Photosynthesis and activity of photosystem II in response to drought stress in Amur Grape (Vitis amurensis Rupr.). Photosynthetica 50:189-196. doi:10.1007/s11099-0120023-9 
Wellburn AR (1994) The spectral determination of chlorophylls a and $\mathrm{b}$, as well as total carotenoids, using various solvents with spectrophotometers of different resolution. J Plant Physiol 144:307-313. doi:10.1016/S0176-1617(11)81192-2

Wellmann E, Schopfer P (1975) Phytochrome-mediated de novo synthesis of phenyalanine ammonia-lyase in cell suspension cultures of parsley. Plant Physiol 55:822-827. doi:10.1104/pp. 55.5.822

Zhong HH, Young JC, Pease EA, Hangarter RP, McClung CR (1994) Interactions between light and the circadian clock in the regulation of CAT2 expression in Arabidopsis. Plant Physiol 104:889-898. doi:10.1104/pp.104.3.889

Zhong HH, Resnick AS, Straume M, McClung CR (1997) Effects of synergistic signaling by phytochrome A and cryptochrome 1 on circadian clock-regulated catalase expression. Plant Cell 9:947-955. doi:10.1105/tpc.9.6.947

Zucker M (1965) Induction of phenylalanine deaminase by light and its relation to chlorogenic acid synthesis in potato tuber tissue. Plant Physiol 40:779-784. doi:10.1104/pp.40.5.779 